\title{
Effects of concrete quality and natural Johannesburg environment on concrete carbonation rate
}

\author{
Jacob Olumuyiwa Ikotun \\ Department of Civil Engineering and Building, Vaal University of Technology, Vanderbijlpark, South Africa
}

\begin{abstract}
This study presents the results of a project undertaken to study the combined effects of concrete quality (binder type, w/b, and duration of initial moist curing) and natural Johannesburg environment on carbonation rate of concretes containing $100 \%$ PC, 35\% fly ash (FA), $50 \%$ ground granulated blast-furnace slag (BS), $10 \%$ silica fume (SF) and (30\% BS $+10 \% \mathrm{SF})$. The results show that apart from the SF blended concretes, the carbonation rate of the SCM blended concretes are higher than the PC concretes. Reducing the $\mathrm{w} / \mathrm{b}$ and increasing the duration of initial moist curing reduced the carbonation rate in the concretes. The indoor exposed concretes have the highest carbonation rates and reducing the $\mathrm{w} / \mathrm{b}$ ratio is more efficient and sustainable in lowering the carbonation rate rather than extending the duration of the initial moist curing.
\end{abstract}

\section{Introduction}

Carbonation is a chemical reaction that occurs when atmospheric $\mathrm{CO}_{2}$ comes into contact with calcium hydroxide present in the concrete pore structure of hardened cement paste [1]. It is a primary influencing factor in corrosion of reinforcement [2].

Concrete carbonation rate is defined as the advancement of the carbonation front in concrete with time [1]. It is influenced primarily by the exposure conditions (relative humidity-RH, temperature, and $\mathrm{CO}_{2}$ concentration) and concrete composition (w/b ratio and binder type) which determines its quality. The duration of early-age curing, coating, and crack in concrete have been reported to have influence on concrete carbonation rate $[3,4]$. Considering these factors, the most effective and sustainable solution to controlling carbonation rate in concrete is rarely discussed in literature.

This study presents the results of a project undertaken to study the combined effects of concrete quality (binder type, $w / b$, and duration of initial moist curing) and natural Johannesburg environment on carbonation rate of concretes containing 100\% PC, 35\% fly ash (FA), $50 \%$ ground granulated blast-furnace slag (BS), $10 \%$ silica fume (SF) and $(30 \% \mathrm{BS}+10 \% \mathrm{SF})$. The study also identifies the efficient and sustainable method of lowering carbonation rate in the concretes.

\section{Materials and method}

\subsection{Concrete specimens preparation}

The binder materials consisted of $100 \%$ PC, $35 \%$ fly ash (FA), $50 \%$ ground granulated blast-furnace slag (BS),
$10 \%$ silica fume (SF) and $30 \% \mathrm{BS}+10 \% \mathrm{SF}$ (BSSF). They satisfied the requirements of SANS 50197 Part 1-2 [5] and SANS 1491-Part 1-3 [6]. The aggregates used were crushed coarse granite stone (maximum size of 19 $\mathrm{mm}$ ) and fine granite sand (nominal size of $4.75 \mathrm{~mm}$ ) that meet the requirements of SANS 1083 [7]. The aggregates were obtained locally from Johannesburg area. Three w/b ratios $(0.95,0.60$ and 0.40$)$ were used to manufacture the concrete cube specimens of size 100 $\mathrm{mm} \times 100 \mathrm{~mm} \times 100 \mathrm{~mm}$. The decision to use the three $\mathrm{w} / \mathrm{b}$ ratios for each of the binder type was to enable comparison of the concretes regarding their carbonation resistance property.

Batching and mixing of the concrete materials were done in a horizontal mixer as described in SANS 10100:2 [8]. A super-plasticiser of modified phosphates group was added to the mixtures to improve the workability of the fresh concrete mixtures where necessary to ensure a minimum slump of 30 to $60 \mathrm{~mm}$, particularly for the mixes of $0.40 \mathrm{w} / \mathrm{b}$ ratio. To study the effect of duration of early-age moist curing on carbonation rate of the concretes, they were cured in water for 7 and 28 days at a temperature of $22 \pm 1{ }^{\circ} \mathrm{C}$. After curing in water, the specimens were exposed to three different Johannesburg environments (indoor, outdoor sheltered and outdoor unsheltered) to assess the effect of exposure conditions on the carbonation rate of the concretes.

\subsection{Exposure site of the concrete specimens}

Three exposure environments were chosen based on the classification specified by BS EN 206-1 [9] as XC1, $\mathrm{XC} 3$ and $\mathrm{XC} 4$ representing moderate, less severe and severe carbonation-induced corrosion exposures. The

\footnotetext{
* Corresponding author: jacobi@vut.ac.za
} 
exposure sites are located within the Hillman building at University of the Witwatersrand, Johannesburg. The lower rooftop of the Hillman building was used as the unsheltered outdoor exposure site. Underneath of a concrete tank placed at the upper rooftop of the Hillman building was used as a sheltered exposure site. A laboratory room with a temperature of $22 \pm 2^{\circ} \mathrm{C}$ and relative humidity of $45 \pm 5 \%$ was used to represent the indoor exposure. The exposure sites were decided upon based on the results of a trial study using five other locations around the University of the Witwatersrand, Johannesburg. It was found that the exposure conditions of relative humidity $(\mathrm{RH}), \mathrm{CO}_{2}$ concentration and temperature were similar in all the exposures considered. Therefore, to avoid disturbance or loss of concrete samples that might have a significant effect on the experimental results, Hillman building was used to expose the concrete specimens. The indoor, outdoor sheltered and outdoor unsheltered exposure environments are shown in Figure 1 with concrete cube specimens in position.

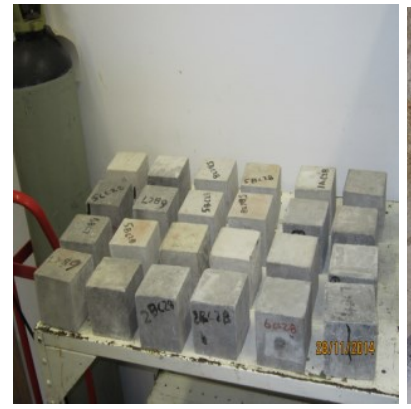

(a)

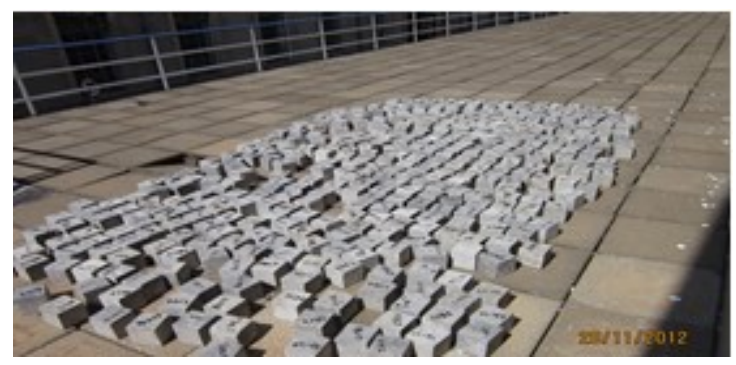

(c)

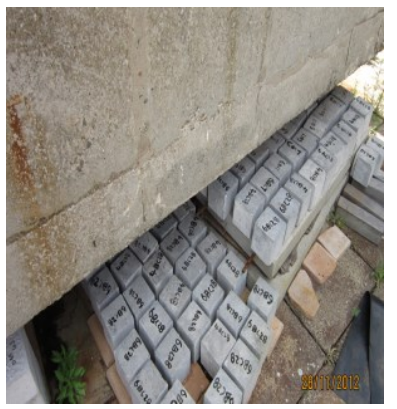

(b) (a) Indoor (b) Sheltered unsheltered

\subsection{Climate measurement of the exposure sites}

Before exposure of the concrete specimens, the environmental conditions $\left(\mathrm{RH}\right.$, temperature and air $\mathrm{CO}_{2}$ concentration) of the exposure sites were measured daily at \pm 1400 hours for a year using a portable climate equipment (Combo IAQ meter). The micro-climate data was analysed for each exposure site regarding minimum and maximum values for the winter and summer periods, thus showing the probable peak and low periods for concrete carbonation.

\subsection{Carbonation test}

The carbonation depths of the concretes were measured at $6,12,18$ and 24 months of the exposure to the environment. Three concrete specimens per a mixture were removed from each of the exposure sites at a testing period. The cube specimens were broken into two along the side faces using a masonry cutter and the cut surface was cleaned of dust and lose particles. The extent of carbonation depth was determined by spraying the freshly cut surface with a solution of phenolphthalein ( $1 \%$ phenolphthalein in $70 \%$ ethyl alcohol). The sprayed concrete cut surface was left for 1 hour \pm 15 minutes. The carbonated zone showed no colouration while the purple-red zone with phenolphthalein solution showed an unaffected zone by carbonation.

The depths of the carbonated zone was measured to an accuracy of $0.05 \mathrm{~mm}$ using a Vernier caliper. The procedure of carbonation measurement was repeated at $6,12,18$ and 24 months of exposure to the natural inland environment for all the concrete cube specimens. An average of 36 readings on three identical specimens was reported as carbonation depth of that particular concrete mix at a testing period.

\section{Results and discussion}

\subsection{Climate results of the exposure sites}

The results of the micro-climate measurement are presented in Table 1. The results are grouped into two periods of the year, namely winter and summer. The winter starts from April to September while the summer starts from October to March in South Africa.

As shown in Table 1, the climate measurements are classified into three exposure types which are indoor, outdoor sheltered and outdoor unsheltered. The range of relative humidity $(\mathrm{RH})$ at the indoor exposure site is relatively lower than the range of $\mathrm{RH}$ at the outdoor exposure sites for the two periods. In any of the exposure, the range of $\mathrm{RH}$ during the summer is higher than the range of humidity measured during the winter. This trend is more noticeable with the outdoor exposures than the indoor exposure and can be because of the increased temperature of the air which holds more moisture during summer than the cold air during the winter period. In South Africa inland environment (Johannesburg), rain falls frequently during the summer period compared to the winter period that receives scanty rainfall. This can also accounts for the marked difference 
Table 1 Exposure conditions at the concrete sites ( \pm 1400 hours)

\begin{tabular}{|c|c|c|c|c|c|c|c|c|c|}
\hline \multirow{2}{*}{ Periods } & \multicolumn{3}{|c|}{ Indoor } & \multicolumn{3}{c|}{ Outdoor sheltered } & \multicolumn{3}{c|}{ Outdoor unsheltered } \\
\cline { 2 - 10 } & $\mathrm{RH}(\%)$ & $\mathrm{T}\left({ }^{\circ} \mathrm{C}\right)$ & $\mathrm{CO}_{2}(\mathrm{ppm})$ & $\mathrm{RH}(\%)$ & $\mathrm{T}\left({ }^{\circ} \mathrm{C}\right)$ & $\mathrm{CO}_{2}(\mathrm{ppm})$ & $\mathrm{RH}(\%)$ & $\mathrm{T}\left({ }^{\circ} \mathrm{C}\right)$ & $\mathrm{CO}_{2}(\mathrm{ppm})$ \\
\hline $\begin{array}{c}\text { April- } \\
\text { September }\end{array}$ & $30-35$ & $19-20$ & $990-1200$ & $35-60$ & $10-19$ & $300-550$ & $30-55$ & $10-19$ & $300-550$ \\
\hline $\begin{array}{c}\text { October- } \\
\text { March }\end{array}$ & $35-40$ & $20-23$ & $650-850$ & $70-80$ & $16-20$ & $250-400$ & $60-80$ & $16-22$ & $250-350$ \\
\hline
\end{tabular}

between the winter and summer RH, especially for the outdoor exposures. The results of the $\mathrm{RH}$ obtained at the concrete exposure locations are expected to have impact on concrete carbonation.

Carbonation reaction does not occur when concrete pores are either completely dry or completely saturated with water [10]. Ballim [1] found that the optimum range of relative humidity for carbonation reaction was between $40 \%$ and $60 \%$. The optimum range of $\mathrm{RH}$ for reinforcement corrosion was found to be between 60 and

It is also evident from the results that the maximum and minimum temperatures measured during the summer period are higher compared to the maximum and minimum temperatures measured during the winter period for all the exposure sites. This can be attributed to the fact that in southern hemisphere solar radiation heats the air more in the summer than winter. This suggests an increase in rate of carbonation reaction [12].

It is also observed from the results that the maximum and minimum $\mathrm{CO}_{2}$ concentrations for the indoor exposure is about three times higher than the maximum and minimum $\mathrm{CO}_{2}$ concentrations of the outdoor exposures. This can be attributed to the enclosed nature of the indoor site which restricts the free circulation of air. Therefore, it is expected that concretes exposed to this indoor environment will experience a relatively higher carbonation rate than those in the outdoor exposure sites. The $\mathrm{CO}_{2}$ concentrations for the two outdoor exposures seem to be similar.

\subsection{Carbonation test results}

The typical plots of carbonation depths against the square root of the exposure times for the PC concretes exposed to an indoor environment are shown in Figure 2. The plots show that for a given concrete exposed to indoor environment, carbonation depth increases along with the exposure time and a higher carbonation depth is noticed with a higher w/b ratio. Similar trends were also observed for the concretes exposed to outdoor sheltered and unsheltered environments. Even though the trend of carbonation depth with exposure time is the same in all the concretes the depth of carbonation varied. This may be due to the influence of the binder type, w/b ratio, duration of the initial moist curing conditions, and moisture condition at the exposure site.
$90 \%$ [3]. However, various authors differ slightly as to the optimum RH range for maximum carbonation and corrosion rates [10]. With the relative humidity ranges cited by Ballim, Alexander and Beushausen [1], it seems that outdoor exposures will favour carbonation process. However, the periodic rewetting of the outdoor concretes during the summer period can significantly reduce the rate of $\mathrm{CO}_{2}$ diffusion through the saturated pores of cement paste matrix $[10,11]$

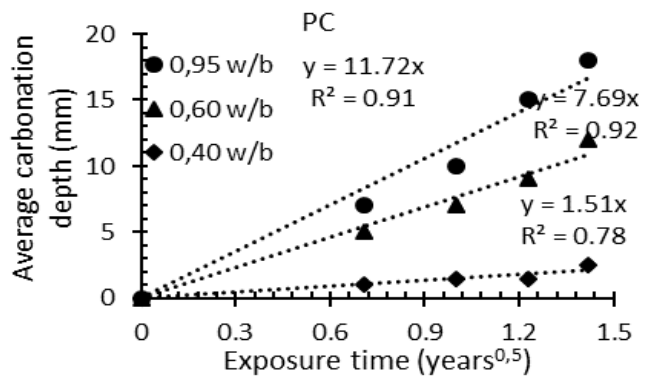

Figure 2 Carbonation depth versus square root of the exposure time - Indoor exposure

Linear regression lines were fitted to the carbonation plots as shown in Figure 2, assuming that carbonation depth is zero at the beginning of the exposure [13]. The slope of the regression lines define the carbonation rate of the concrete mixtures.

As evident from Figures 3 and 4 the measured carbonation rate of the concretes varies due to the influences of the concrete mixture composition (w/b ratio and binder type), duration of the initial wet curing and exposure conditions at the respective concrete sites. The influence of these factors are discussed in sections 3.2.1 and 3.2.2.

\subsubsection{Effect of exposure conditions on carbonation rate}

Figures 5, 6 and 7 show that for a given concrete initially cured for a specified period; the indoor exposed concretes have the highest carbonation rates compared to the concretes exposed to the outdoor environmental conditions. Even though the relative humidity of the indoor environment seems not to support optimum carbonation reaction in the concretes, its $\mathrm{CO}_{2}$ concentration was found higher than the outdoor exposures. This shows that the carbonation reaction of the indoor exposed concretes is controlled by the $\mathrm{CO}_{2}$ diffusion rather than relative humidity. 


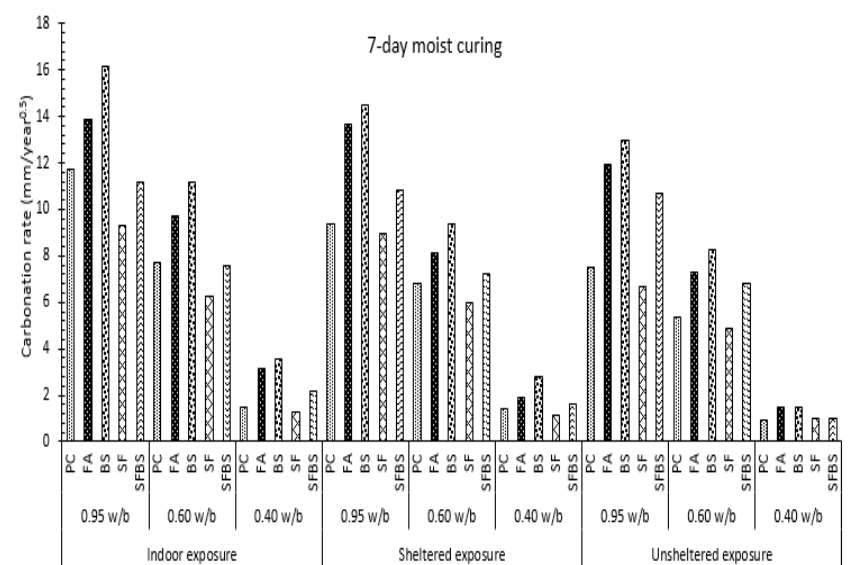

Figure 3 Carbonation rate of the concretes cured in water for 7days

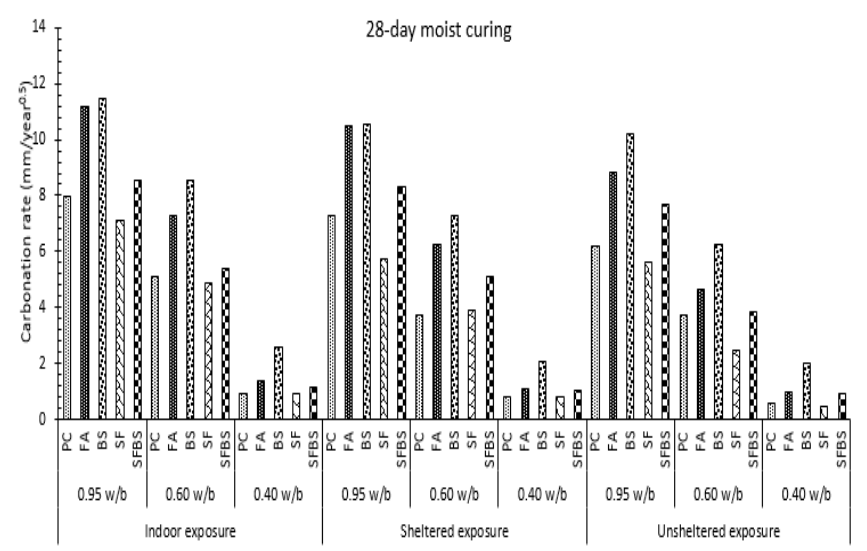

Figure 4 Carbonation rate of the concretes cured in water for 28-days

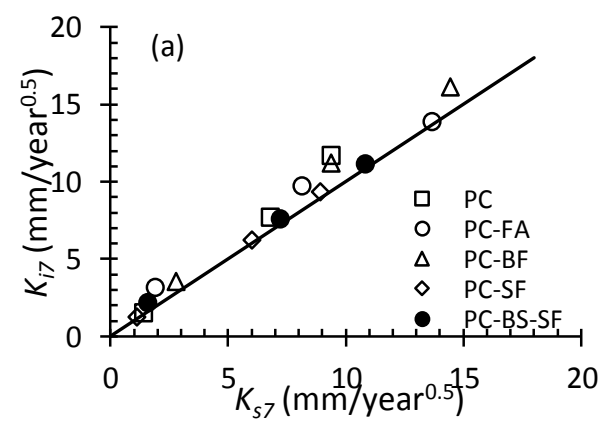

Figure 5 Indoor carbonation rate $\left(K_{i 7}\right)$ versus outdoor sheltered carbonation rate $\left(K_{s 7}\right)$

In comparing the carbonation rate of the concretes exposed to sheltered and unsheltered exposure conditions (Figure 7), it is evident that carbonation rate is higher in the sheltered concretes than the unsheltered concretes. This is because capillary pores of the outdoor exposed concretes are usually filled with moisture during the wet season thereby hindering $\mathrm{CO}_{2}$ diffusion into the concrete pores. The carbonation reaction can only proceed once samples have dried sufficiently to the depth at which the process stopped [4,14]. This shows that for a concrete exposed externally to Johannesburg environment, carbonation reaction is controlled by the length of wetting and drying periods.

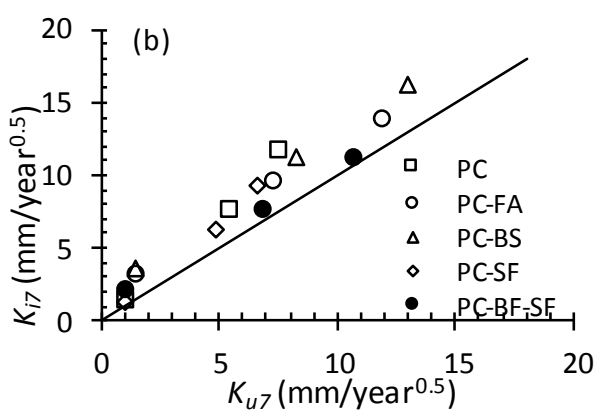

Figure 6 Indoor carbonation rate $\left(K_{i 7}\right)$ vs outdoor unsheltered carbonation rate $\left(K_{u 7}\right)$

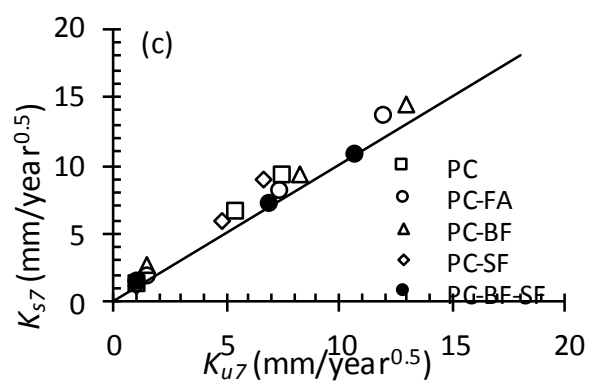

Figure 7 Carbonation rate of outdoor sheltered $\left(K_{S 7}\right)$ vs outdoor unsheltered $\left(K_{u}\right)$

\subsubsection{Effect of $w / b$ ratio and binder type on carbonation rate}

It is evident from Figures 3 and 4 that for a given concrete exposed to any of the inland environments, carbonation rate increases with an increase in $\mathrm{w} / \mathrm{b}$ ratio. This may be due to the increase in capillary pore size and interconnectivity between the pores at a higher $\mathrm{w} / \mathrm{b}$ ratio since $\mathrm{w} / \mathrm{b}$ ratio primarily determines the gel/space ratio, capillary porosity and concrete permeability [15]. The increase in carbonation rate of the higher $w / b$ ratio concretes may also be attributed to the fact that the amount of Portlandite decreases with an increase in $\mathrm{w} / \mathrm{b}$ ratio. This is because a less cementitious material is present in a concrete manufacture with a higher $\mathrm{w} / \mathrm{b}$ ratio compared to a lower $\mathrm{w} / \mathrm{b}$ ratio [16].

The influence of binder type on the carbonation rate of the concretes for each of the exposure site is also shown in Figures 3 and 4. It is evident that for a constant $\mathrm{w} / \mathrm{b}$ ratio, the SCM blended concretes showed higher carbonation rates compared to the PC concretes exposed to the same environment. However, SF blended concretes show a superior carbonation resistance compared to the PC, FA and BS blended concretes.

Moreover, despite the fact that the pore structure of SCM blended concretes are usually very dense as a result of their finer particle size and their filler effect with PC and aggregates, their carbonation rates are higher compared to the PC concretes. This suggests that pore structure may not be the only parameter that control the carbonation rate in concrete.. For a given $\mathrm{w} / \mathrm{b}$ ratio, the amount of $\mathrm{Ca}(\mathrm{OH})_{2}$ in the SCM blended concrete is lower compared to that of PC concrete. This is usually 
because of the reduction in the PC content of the SCM blends. The available $\mathrm{Ca}(\mathrm{OH})_{2}$ in the SCM concrete is partly consumed during the pozzolanic reaction of the SCM $[17,18]$. The pozzolanic reaction of the SCM blend reduces the amount of calcium hydroxide available for carbonation reaction and can be responsible for the faster rate of carbonation in the SCM blended concretes.

It is well noted by many studies that, the reactivity of SF at early age is higher compare to other SCM due to its particle fineness, this depicts a greater consumption of $\mathrm{Ca}(\mathrm{OH})_{2}$ with the expectation that carbonation rate would be greater in SF blended concrete than the PC concrete. The improved performance of SF blended concrete can be attributed to its particle fineness and higher PC content compared to FA and BS blended concretes [18-21].

\subsubsection{Effect of duration of initial moist curing on carbonation rate}

The effect of the initial moist curing duration on concrete carbonation rates is illustrated in Figure 8. It is evident that for a given concrete in an exposure, extending the initial moist curing duration from 7 days to 28 days reduces the carbonation rate. The decrease in the carbonation rate due to the extension in the early-age curing conditions may be because extending the moist curing duration increases the degree of hydration [15]. During hydration, the capillary porosity decreases due to consumption of water producing hydration products that fill the capillary pore spaces. As the hydration continues, the size of the capillary pores and the connectivity between the pores decreases, particularly at the cover zone.

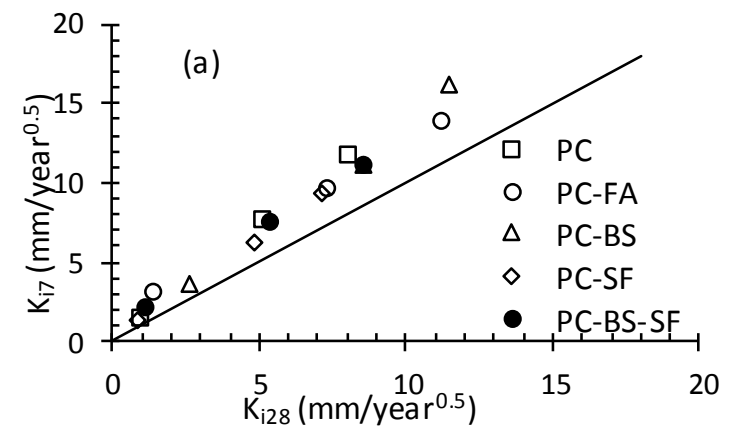

Figure 8 Indoor carbonation rate $\left(\mathrm{K}_{\mathrm{i}}\right)$ vs indoor carbonation rate $\left(\mathrm{K}_{\mathrm{i} 28}\right)$

Moreover, extending the initial moist curing of concrete is not the only method of reducing carbonation rate in concrete in an exposure condition. Other methods such as reducing the $\mathrm{w} / \mathrm{b}$ ratio offers greater reductions in carbonation rate of the concretes compared to extending the initial moist curing duration. For example, a PC-FA concrete of $0.95 \mathrm{w} / \mathrm{b}$ ratio exposed to the indoor environment was initially moist cured in water for seven days. The same PC-FA concrete was initially moist cured for 28 days in water, the percentage reduction in carbonation rate is $19 \%$. Reducing the $\mathrm{w} / \mathrm{b}$ ratio from 0.95 to 0.60 for the same concrete in a similar environment gives a carbonation rate reduction of $30 \%$. A further reduction of the $\mathrm{w} / \mathrm{b}$ ratio from 0.60 to 0.40 gives a carbonation rate reduction of $67 \%$ which is the highest compared to extending the early-age moist curing duration from 7 to 28 days. The trend is similar in all the concretes in all the exposures.

The analysis in this study shows that reducing the $\mathrm{w} / \mathrm{b}$ ratio seems to be more effective and sustainable (in terms of water conservation) in reducing the carbonation rate in concrete than extending the duration of the initial moist curing.

\section{Conclusion}

- Apart from the SF blended concretes, the carbonation rate of the SCM blended concretes are higher than the PC concretes.

- The order of carbonation rate (maximum to minimum) regarding the exposure conditions is: indoor $\rightarrow$ outdoor sheltered $\rightarrow$ outdoor unsheltered.

- Reducing the $w / b$ and increasing the duration of initial moist curing reduced the carbonation rate in the concretes

- The indoor exposed concretes have the highest carbonation rates

- Reducing the $\mathrm{w} / \mathrm{b}$ ratio is more efficient and sustainable in lowering the carbonation rate than extending the duration of the initial moist curing.

The Concrete Institute (TCI), South Africa, Bradlow Foundation and Postgraduate Merit Award of the University of the Witwatersrand are acknowledged for their financial support. Vaal University of Technology is acknowledged for travel grant to attend this conference.

\section{References}

[1] Ballim Y, Alexander MG, Beushausen $\mathrm{H}$. Durability of concrete. In: Owens G, editor. Fulton's Concr. Technol. 9th ed., Midrand: Cement and Concrete Institute, South Africa; 2009, p. 155-88.

[2] Ahmad S. Reinforcement corrosion in concrete structures, its monitoring and service life prediction-a review. Cem Concr Compos 2003;25:459-71.

[3] Ballim Y, Reid JC. Reinforcement corrosion and the deflection of RC beams - An experimental critique of current test methods. Cem Concr Compos 2003;25:625-32.

[4] Hills TP, Gordon F, Florin NH, Fennell PS. Statistical analysis of the carbonation rate of concrete. Cem Concr Res 2015;72:98-107. doi:10.1016/j.cemconres.2015.02.007.

[5] SANS 5861-2: 2006. South African National Standard Concrete tests Part 2: Sampling of freshly mixed concrete. 2006.

[6] SANS 1491 Part 1-3 -2005. South African Standard: Portland cement extenders. Pretoria: 2005. 
[7] SANS 1083. South African Standard: Aggregates from natural sources-Aggregates for concrete. 2006.

[8] SANS 10100:2-2000. South African Standard:The structural use of concrete Part 2: Materials and execution of work. Pretoria: 1992.

[9] British Standards Institution. Concrete Complementary British Standard to BS EN 2061.

[10] Ballim Y, Lampacher BJ. Long-term carbonation of concrete structures in the Johannesburg environment. SAICE 1996:5-9.

[11] Alexander MG, Mackechnie JR, Yam W. Carbonation of concrete bridge structures in three South African localities. Cem Concr Compos 2007;29:750-9.

[12] Tuutti K. Corrosion of Steel in Concrete. Stockholm: Swedish Cement and Concrete Research Institute S-100 44 Stocholm; 1982.

[13] Ikotun JO. Benefits of utilising oil drill cuttings as filler replacement in cement and ternary cement concretes. MSC Thesis, University of Dundee, Dundee, UK, 2010.

[14] Ananmalay N. Characterising the strength and durability performance of South African Silica fume concretes. MSc thesis. University of the Witwatersrand, Johannesburg, South Africa, 1996.
[15] Garboczi EJ. Microstructure and transport properties of concrete. In: Kropp J, Hilsdorf H., editors. Perform. Criteria Concr. Durab., London: E \& FN SPON; 1995, p. 198-212.

[16] Salvoldi BG, Beushausen H, Alexander MG. Oxygen permeability of concrete and its relation to carbonation. Constr Build Mater 2015;85:307.

[17] Dalage P, Aitcin P. Influence of condensed silica fume on the pore-size distribution of concretes. Ind Eng Chem Prod Res Dev 1983;22:286-90.

[18] Terence CH. Silica Fume User's Manual. Lovettsville, VA: 2005.

[19] King D. The Effect of Silica Fume on the Properties of Concrete as Defined in Concrete Society Report 74, Cementitious Materials. 37th Conf. Our World Concr. Struct. 29 - 31 August 2012, Singapore: 2012.

[20] Arum C, Moya D. Effect of packing densities of aggregates on the workability and compressive strength. 4th West Africa Built Environ. Res., 2012, p. 301-14.

[21] Buss K. Ternary combination concretes using GGBS , fly ash \& limestone. PhD Thesis, University of Dundee, Dundee, UK, 2013. 